\title{
Effects of Virtual Reality-Based Physical And Psychological Exercise On Depression In Stroke Patients : A Meta-Analysis
}

Hebing Liu

Jilin University

Zhaohua Cheng

Jilin University

Shuo Wang

Xuzhou Medical University

Yong Jia ( $\sim$ jiay0023@163.com )

Jilin University

Chen Li

Jilin University

\section{Research Article}

Keywords: Virtual reality, Meta-analysis, Depression, Stroke

Posted Date: October 25th, 2021

DOI: https://doi.org/10.21203/rs.3.rs-982395/v1

License: (c) (i) This work is licensed under a Creative Commons Attribution 4.0 International License. Read Full License 


\title{
Effects of virtual reality-based physical and psychological exercise on depression in stroke patients : a meta-analysis
}

\author{
Hebing Liu ${ }^{\mathrm{a}, 1}$, Zhaohua Cheng ${ }^{\mathrm{a}, 1}$, Shuo Wang ${ }^{\mathrm{b}}$, Yong Jia ${ }^{\mathrm{c}, *}$, Li Chen ${ }^{\mathrm{c}, * *}$ \\ ${ }^{a}$ The Second Hospital, Jilin University, No. 218 Ziqiang Street, Changchun, Jilin 130021, China \\ ${ }^{\mathrm{b} S}$ Shool of Nursing, Xuzhou Medical University, Tongshan Road, Xuzhou, Jiangsu 221004, China \\ 'School of Nursing, Jilin University, No.965 Xinjiang Street, Changchun, Jilin 130021, China
}

Background: Virtual Reality (VR) has been widely used in health-related fields. The aim of this study was to assess the effectiveness of virtual reality-based physical and psychological exercise on depression.

Methods: A total of 752 patients with stroke from 11 randomized controlled trial (RCT) studies were included in this meta-analysis and the studies derived from 6 electronic databases searched from database inception to August 2021. For continuous results, the standardized mean differences (SMDs) and 95\% confidence intervals (CIs) were calculated to synthesize the effects.

Results: The meta-analysis showed that compared with control group, VR-based interventions significantly decreased the depression scale score $(\mathrm{SMD}=-0.71,95 \% \mathrm{CI}$ : $-1.32,-0.10)$ in the subjects. The results showed that the the patient age and total intervention time had a significant impact on the outcome of depression. The smaller the age and longer the intervention duration, the greater the impact on the outcome of depression.

Conclusions: The current meta-analysis indicated the virtual reality-based physical and psychological exercise has a significant effect on depression in stroke patients compared to controls. The study showed an outstanding reduction in depression for aged under 60 participants and intervention longer than 8 weeks. At the same time, clinical studies of different ages and different intervention time also need further in-depth study.

Keywords: Virtual reality; Meta-analysis; Depression; Stroke 
* Corresponding author.

** Corresponding author at: No.965 Xinjiang Street, Changchun, Jilin 130021, China.

Email address: jiay0023@163.com, chenli06060023@126.com

${ }^{1}$ These authors contributed equally to this work.

\section{Introduction}

Stroke, as one of the most common neurological diseases resulting in permanent disability in adults ${ }^{[1]}$, has become a widespread health problem that affects people's daily independent living ${ }^{[2-4]}$. For the patients with stroke, the risk of impaired psychological health and depression increases ${ }^{[5]}$. About a third of stroke survivors experience post-stroke depression ${ }^{[6]}$. The patients with depression can lead to loss of interest and happiness, and produce anxiety and fear and hostility and sadness and anger ${ }^{[7]}$. For the stroke patients, post-stroke depression not only delays the recovery of neurological deficits but also has a negative impact on the functional recovery and rehabilitation ${ }^{[8-11]}$, resulting in a decline in the quality of life and increases the mortality ${ }^{[12]}$. Such psychological states may lead to reduced motivation and low adherence to rehabilitation training and increased burden of caregivers ${ }^{[5]}$.

The current intervention methods mainly include drugs and psychotherapy. Studies have shown that up to $43 \%$ of patients with major depressive disorder may discontinue antidepressants due to adverse reactions during treatment ${ }^{[13]}$. So non-drug interventions are getting more and more attention. In recent years, virtual reality-based intervention has been found to be effective for depression ${ }^{[14-16]}$. Virtual reality (VR) is a computer-generated high-tech simulation system which can create a a sense of being there using computer electronic information simulation technology, and has three basic characteristics including immersion and interaction and imagination. VR training, as a dynamic training method in line with daily life activities, can carry out active rehabilitation training from three levels of repetitive, feedback and motivation in a computer simulation of three-dimensional space. 
Therefore, this method can increase patients' initiative and subjective initiative through multi-sensory feedback.

The interventions based on VR are diverse, including virtual reality exposure therapy ${ }^{[17-18]}$, virtual reality cognitive behavioral therapy ${ }^{[19-20]}$ and virtual reality-based physical $^{[21]}$ and psychological exercise ${ }^{[22]}$ etc. Compared with traditional therapy, VR is more convenient to use, flexible and changeable in treatment content, more positive in users' attitude, and more pleasant in experience ${ }^{[23]}$. A variety of immersive games can enable patients to have a deeper interest, and thus improve their subjective initiative resulting in various rehabilitation training be actively completed by patients $^{[24]}$. As a result, a virtuous cycle can be formed, and their functional level be improved $^{[25]}$.

Compared to traditional teach-based training, VR is thought to reduce learning difficulty and make training safer ${ }^{[26]}$. We have witnessed the development of tele-medicine in the last few years, and the tele-medicine overcome the barriers caused by distance and lower the cost of healthcare and encourage continuity of care $^{[27]}$. However, the application of VR technology in the treatment of depression has not been promoted in clinical practice, and its effect is still being explored.

A meta-analysis ${ }^{[28]}$ has explored the effects of game-based digital interventions on depression in adults in 2014. The meta-analysis revealed a moderate effect size of the game interventions for depression therapy at post-treatment, but no specific analysis was made. Another meta-analysis on the effectiveness of virtual reality-based interventions for symptoms of anxiety and depression in adults was published in 2018 ${ }^{[29]}$. However, depression was a secondary outcome measure, and the literature included was incomplete with only 10 articles. In 2021, a meta-analysis ${ }^{[30]}$ has explored the effects of VR exergames for promoting older adults' cognition and ameliorating depressive symptoms. Thus, the purpose of this study was to specifically analyze the effects of virtual reality-based physical and psychological exercise on depression in stroke patients. 


\section{Methods}

This systematic review and meta-analysis were conducted in accordance with the Preferred Reporting Items for Systematic Reviews and Meta-Analyses (PRISMA) guidelines $^{[31]}$. A study protocol was registered at PROSPERO (CRD42020194244).

\subsection{Literature inclusion and eligibility criteria}

Studies were selected based on the following criteria: (a) study design must be randomized controlled trials (RCTs); (b) the participants are stroke patients; (c) interventions in the experiment group are based on VR physical or psychological exercise; (d) interventions in the control group are not based on VR. If there are both active treatment group and waiting-list group in the control group, the waiting-list group is selected; (e) depression is the primary outcome, and it must be measured. Useful data (e.g., sample size, mean and standard deviation) were clearly reported in the published paper or could be retrieved through contacting corresponding author of primary studies; (f) full-text articles published in peer-reviewed journals; (g) the number of participants including the experiment group and the control group is over 10; (h) the articles are published in Chinese or English.

\subsection{Data sources and search strategy}

We collected a comprehensive literature from the three English databases and three Chinese databases: Medline, PubMed, Web of Science, Chinese National Knowledge Infrastructure (CNKI), SinoMed (CBM), Wanfang databases. Six databases were conducted until August 2021. The following search items will be adopted: virtual reality, VR, virtual environment, depression, depressive symptoms, depressive disorder, stroke, randomized controlled trial. Search strategies were included as Supplementary Appendix 1.

\subsection{Study selection}

Duplicate papers would be removed first before undertaking the screening. Two reviewers checked independently titles and abstracts of the retrieved articles 
according to the review criteria. Any disagreement was resolved by consensus and a third reviewer would arbitrate disagreements.

\subsection{Data Extraction}

An electronic form was established to extract substantial contents, which included the first author and publish year of the study, the sample size, nation, age, condition, pre-treatment and post-treatment score for depression, interventions in experimental group and control group, the assessment tools for outcome measures and dropouts. Data extraction was carried out independently by two authors. Any disagreement will be resolved by consensus and a third reviewer will arbitrate disagreements.

\subsection{Quality Assessment}

Based on the Cochrane Collaboration Risk of Bias tool ${ }^{[32]}$, the assessment of methodological quality of included studies was assessed respectively independently by two review authors to evaluate the potential bias risk. Six perspectives pertained to bias risk including random sequence generation, allocation concealment, blinding of participants and personnel, blinding of outcome assessment, and selective reporting, and other issues were also evaluated. Using this tool, risk of bias was judged as 'Low', 'High' or 'Unclear'.

\subsection{Data Analysis}

The software Review Manager 5.2 was used to analyze the outcome indicators of the included studies. Because different scales were used to measure the same outcomes for the measures of depressive, we calculated the standardized mean difference (SMD) with 95\% confidence intervals (CIs) and then combined these values for the meta-analysis. $I^{2}$ was used to evaluate the heterogeneity in this study. When $I^{2} \leq 24 \%$, there is no heterogeneity; $25 \% \leq I^{2} \leq 49 \%$, low heterogeneity; $50 \% \leq$ $I^{2} \leq 74 \%$, mild heterogeneity; $I^{2} \geq 75 \%$, high heterogeneity ${ }^{[32]}$. When $I^{2}>50 \%$, the substantial heterogeneity was considered and a random effect model was selected, otherwise, a fixed effect model was selected for analysis ${ }^{[25]}$. Publication bias was assessed through visual analysis, with roughly symmetrical funnel plots indicating a 
low risk of publication bias and asymmetrical funnel plots indicating a high risk of publication bias. The sensitivity analysis was used to determine the source of heterogeneity by excluding studies one by one and presented in a summary table. We also conducted subgroup analyses based on depression status, age of the participants and duration.

\section{Result}

\subsection{Study selection}

Fig. 1 shows the study selection process. In total, 2193 records were identified by searching the databases, and 1256 potentially eligible articles were identified after removing duplicates. 62 studies were retrieved and reviewed by a more detailed assessment after screening the titles and abstract. After reviewing the full-text articles for eligibility, 11 studies were included.
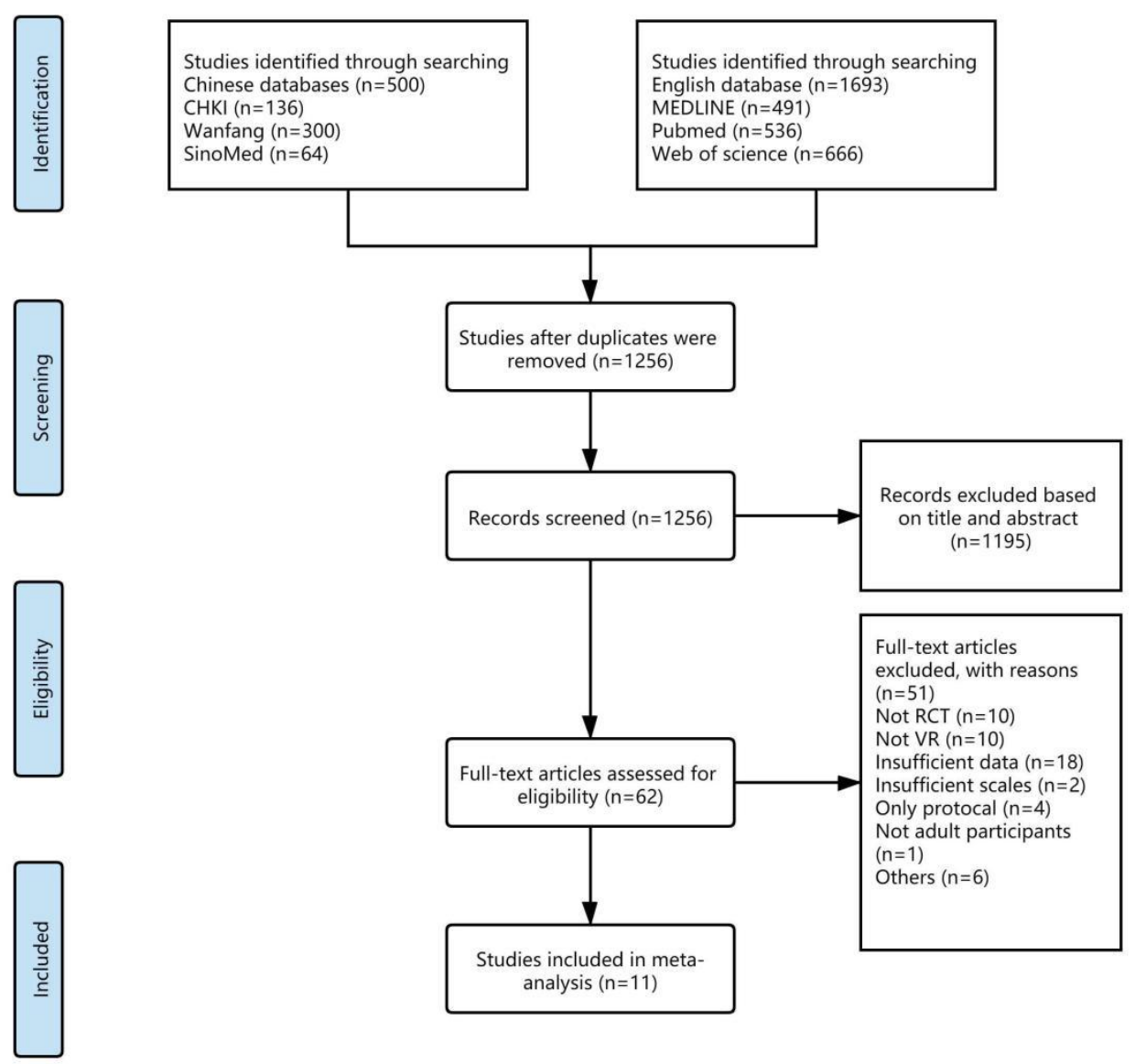

Fig.1. Flow chart of the study selection process in meta-analysis. 
Table 1 Characteristics of the studies included the meta-analysis

\begin{tabular}{|c|c|c|c|c|c|c|c|c|c|c|}
\hline Author, year & Country & $\begin{array}{l}\text { Sample } \\
\text { size }\end{array}$ & Age & Condition & $\begin{array}{l}\text { Pre-treatment score } \\
\text { for depression }\end{array}$ & $\begin{array}{l}\text { Post-treatment } \\
\text { score for depression }\end{array}$ & Experimental group & $\begin{array}{l}\text { Control } \\
\text { group }\end{array}$ & $\begin{array}{l}\text { Depression } \\
\text { Measures }\end{array}$ & $\begin{array}{l}\text { Dropouts } \\
\text { and reasons }\end{array}$ \\
\hline \multirow{2}{*}{$\begin{array}{l}\text { Adomaviciene } \\
\text { et al., } 2019\end{array}$} & \multirow[t]{2}{*}{ Lithuania } & \multirow[t]{2}{*}{42} & EG: $62 \pm 5.9$ & \multirow[t]{2}{*}{ Stroke } & EG: $8.40 \pm 4.44$ & EG: $8.48 \pm 4.43$ & (1) & \multirow[t]{2}{*}{$(2)$} & \multirow[t]{2}{*}{ HADS-D } & \multirow[t]{2}{*}{ (3) } \\
\hline & & & CG: $66 \pm 7.0$ & & CG: $5.41 \pm 3.12$ & CG: $4.94 \pm 3.09$ & 45 minutes/day, 10 sessions & & & \\
\hline \multirow{2}{*}{$\begin{array}{l}\text { Bi } \\
\text { et al.,2020 }\end{array}$} & \multirow[t]{2}{*}{ China } & \multirow[t]{2}{*}{120} & EG: $68.3 \pm 8.3$ & \multirow{2}{*}{$\begin{array}{l}\text { post stroke } \\
\text { depression }\end{array}$} & EG: $70.37 \pm 10.13$ & EG: $46.33 \pm 7.42$ & (4) & \multirow[t]{2}{*}{ (5) } & \multirow[t]{2}{*}{ SDS } & \multirow[t]{2}{*}{$\mathrm{nr}$} \\
\hline & & & CG: $67.9 \pm 6.1$ & & CG: $68.13 \pm 10.83$ & CG: $56.73 \pm 4.81$ & (6) & & & \\
\hline \multirow{2}{*}{$\begin{array}{l}\text { Kim } \\
\text { et } 1.2020\end{array}$} & \multirow[t]{2}{*}{ Korea } & \multirow[t]{2}{*}{24} & EG: $71.92 \pm 3.23$ & stroke & EG: $16.00 \pm 1.04$ & EG: $12.16 \pm 0.71$ & (7) & \multirow[t]{2}{*}{ (8) } & \multirow[t]{2}{*}{ K-GDS } & \multirow[t]{2}{*}{$\mathrm{nr}$} \\
\hline & & & CG: $72.08 \pm 4.46$ & & CG: $17.08 \pm 1.37$ & CG: $12.75 \pm 0.35$ & (9) & & & \\
\hline \multirow{2}{*}{$\begin{array}{l}\text { Lin } \\
\text { et al., } 2020\end{array}$} & \multirow[t]{2}{*}{ Taiwan } & \multirow[t]{2}{*}{145} & EG:64.5 \pm 13.5 & \multirow[t]{2}{*}{ Stroke } & EG: $12.1 \pm 2.5$ & EG: $9.3 \pm 3.2$ & 60 minutes/day, 5 days/week & \multirow[t]{2}{*}{ (10) } & \multirow[t]{2}{*}{ HADS-D } & EG: $n=0$ \\
\hline & & & CG: $66.9 \pm 13.3$ & & CG: $10.3 \pm 4.8$ & CG: $10 \pm 4.5$ & (11) & & & (12) \\
\hline \multirow{2}{*}{$\begin{array}{l}\text { Rogers } \\
\text { et al.,2019 }\end{array}$} & \multirow[t]{2}{*}{ Australia } & \multirow[t]{2}{*}{21} & EG: $64.3 \pm 17.4$ & \multirow{2}{*}{$\begin{array}{l}\text { sub-acute } \\
\text { stroke }\end{array}$} & EG: $32.6 \pm 9.1$ & EG: $24.5 \pm 6.6$ & (13) & (14) & \multirow[t]{2}{*}{ NFI } & \multirow[t]{2}{*}{$\mathrm{nr}$} \\
\hline & & & CG: $64.6 \pm 12.0$ & & CG: $33.9 \pm 13.9$ & CG: $30.6 \pm 10.6$ & 30-40 minutes/day, 4week & $3 \mathrm{~h} /$ day & & \\
\hline Rooij & Netherland & 55 & EG: $65 \pm 9.6$ & stroke & EG: $4.39 \pm 3.35$ & EG: $4.04 \pm 3.49$ & VR gait training (VRT) & $(15)$ & HADS-D & $\mathrm{EG}=0$ \\
\hline et al.,2021 & & & CG: $61 \pm 13.3$ & & CG: $3.54 \pm 2.28$ & CG: $2.83 \pm 2.16$ & (16) & (17) & & (18) \\
\hline Song & Korea & 40 & EG: $51.37 \pm 40.6$ & stroke & EG: $21.2 \pm 3.8$ & EG: $14.1 \pm 2.4$ & (19) & $(20)$ & BDI & $\mathrm{nr}$ \\
\hline et al., 2015 & & & CG: $50.10 \pm 7.83$ & & CG: $19.6 \pm 3.2$ & CG: $17.5 \pm 2.7$ & (21) & & & \\
\hline Sun & China & 64 & EG: $50.5 \pm 9.6$ & post stroke & EG: $21.8 \pm 3.4$ & EG: $8.7 \pm 2.8$ & $(22)$ & (23) & HAMD & $\mathrm{nr}$ \\
\hline et al., 2018 & & & CG: $53.0 \pm 8.7$ & depression & CG: $20.8 \pm 3.2$ & CG: $12.3 \pm 3$ & (24) & & & \\
\hline $\mathrm{Xu}$ & China & 72 & EG: $52.33 \pm 5.37$ & post stroke & EG: $15.56 \pm 3.11$ & EG: $10.17 \pm 2.01$ & $(25)$ & (26) & HAMD & $\mathrm{nr}$ \\
\hline et al.,2020 & & & CG: $51.67 \pm 4.61$ & tilting syndrome & CG: $16.72 \pm 3.23$ & CG: $14.26 \pm 2.95$ & (27) & $(28)$ & & \\
\hline $\mathrm{Yu}$ & China & 109 & EG: $39.56 \pm 4.83$ & ischemic stroke & EG: $28.15 \pm 1.23$ & EG: $11.25 \pm 2.12$ & (29) & $(30)$ & HAMD & $\mathrm{nr}$ \\
\hline et al.,2020 & & & CG: $40.24 \pm 4.83$ & & CG: $29.23 \pm 2.24$ & CG: $16.24 \pm 1.64$ & 20-30 min/time, twice/day & & & \\
\hline Zhang & China & 60 & EG: $67.80 \pm 5.76$ & stroke & EG: $8.83 \pm 3.09$ & EG: $7.97 \pm 2.4$ & $(31)$ & $(32)$ & HADS-D & $\mathrm{nr}$ \\
\hline et al., 2017 & & & CG: $69.30 \pm 5.87$ & hemiplegia & CG: $8.30 \pm 2.89$ & CG: $7.57 \pm 2.14$ & (33) & & & \\
\hline
\end{tabular}


EG, Experimental group; CG, Control group; HADS-D, Hospital Anxiety and Depression Scale for Depression; SDS, Self-rating depression scale; HAMD, Hamilton Depression Scale; BDI, Beck Depression Inventory; K-GDS, Korea geriatric depression scale; VRGs, virtual reality games; VRT, virtual reality gait training; NFI, Neurobehavioral Functioning Inventory; nr, not report. (1)virtual reality Kinect-based system training+conventional rehabilitation training: virtual games+conventional rehabilitation training. (2)conventional rehabilitation training+armeo Spring robot-assisted training. (3)High blood pressure(n=6), Heart rate problems(n=4), Intolerance of physical load(n=3), Fast fatigue(n=4), Painful shoulder syndrome(n= 3), Fever(n=5), Refusal to participate in the study $(n=3)$. (4)VR psychological rehabilitation+conventional rehabilitation training: walking across zebra crossings, boating on the river, playing table tennis indoors and having a dialogue with the characters in the virtual scene. (5)conventional rehabilitation training. (6)40-60 minutes/day, 3-4 days/week, 8 weeks. (7)VR-based trunk-centered stabilization exercise. (8)trunk-centered stabilization exercise. (9)30 minutes/day, 3 days/week, 4 weeks. (10)conventional rehabilitation training(postural training, facilitation techniques, stretching exercise. (11)VR exercise+daily conventional occupational and physiotherapy. (12)CG: $\mathrm{n}=2$ (transferred intensive care unit). (13)VR exercise+daily conventional occupational and physiotherapy. (14)daily conventional occupational and physiotherapy. (15)conventional treadmill training+functional gait exercises. (16)consisted of 2 30-minute sessions per week for 6 weeks (12 sessions). (17)consisted of 2 30-minute sessions per week for 6 weeks (12 sessions). (18)CG=3(2recurrent stroke,1 reason unknown because of non-response). (19)VRGs: 10-pin bowling, skiing, golf, ground walking, walking over obstacles, climbing stairs. (20)ergometer bicycle training. (21)30 minutes/day, 5 days/week, 8 weeks. (22)VRGs+conventional rehabilitation training+psychological intervention: Racing, big fish eat small fish, trajectory flight, trajectory tracking, picture matching, wipe the table, sports watch video, catch treasure, rebound ball, etc. (23)conventional rehabilitation training+psychological intervention. (24)15 minutes/day, 6 days/week, 8 weeks. (25)VR balance function training(track tracking training, mushroom picking training and walking training). (26)conventional rehabilitation training(range of motion training, balance function training, weight transfer training). (27)50 minutes/day, 6 days/week, 4 weeks. (28)50 minutes/day, 6 days/week, 4 weeks. (29)VRGs+stroke unit comprehensive treatment: parkour, matching cards, racing cars, squeezing toothpaste, holding a water glass, twisting towel. (30)stroke unit comprehensive treatment (internal medicine treatment, rehabilitation training;Comprehensive care, psychosocial and behavioral interventions, and post-rehabilitation career planning and vocational competency training)/conventional rehabilitation training. (31)VRGs+conventional rehabilitation training: Fruit cognition, life tool cognition, fruit cutting, ski event motion sensing game, speed skateboard.. (32)conventional rehabilitation training: (1)training for the maintenance of range of motion of lower limbs; (2)muscle strength training; (3)Bridge movement; (4)training of gravity shift; (5)sitting and standing balance training; (6)sit-stand posture transfer training; (7) General gait training: flat ground walking training, turn in all directions, walk sideways, cross walk, up and down stairs, etc. (33)30 minutes/day, 5 days/week, 6 weeks. 


\subsection{Characteristics of included studies}

Table 1. shows the characteristics of included studies. In this research, the 11 included RCT papers were published between 2015 and 2021, including six English studies and five Chinese studies. The population sizes of the trials ranged from 21 to 145. The participants were post stroke depression in two studies ${ }^{[12,22]}$. The duration of each intervention ranged from 15 to 60 minutes. The intervention period was as short as four weeks, and sometimes as long as eight weeks. Assessment tools for depression included Hospital Anxiety and Depression Scale for Depression, Beck Depression Inventory, Hamilton Depression Scale, Self-rating depression scale, Korea geriatric depression scale and Neurobehavioral Functioning Inventory.

\subsection{Risk of bias}

The risk-of-bias results are summarized for the included studies in Fig.2. All the studies were described as randomized. Nine studies ${ }^{[5,12,23,22,33-37]}$ described the method of randomization used. Information on concealment of treatment allocation was reported in three studies ${ }^{[5,23,34]}$. No study described clearly blinding of the participants and personnel. Two trials ${ }^{[22,34]}$ reported adequate blinding of the outcome assessor. There was no study at unclear risk of bias about incomplete outcome data. The risk of bias due to selection reporting was low across all the studies. No other potential bias was revealed in all studies.

\subsection{The effect of VR-based interventions on depression}

We included 11 studies with a total of 752 patients. The random-effects model was used to pool the SMDs and corresponding 95\% CIs. As shown in Fig.3(A), the results showed that depression scores in the VR group was significantly lower than that in the control group after the intervention (SMD $=-0.71,95 \% \mathrm{CI}:-1.32,-0.10$ ). Significant heterogeneity was observed among the studies $\left(I^{2}=92 \%, p<0.00001\right)$. The funnel plot did not show significant asymmetry in Fig.4. After sensitivity analysis included as Supplementary Appendix 2, the heterogeneity did not decrease significantly. 


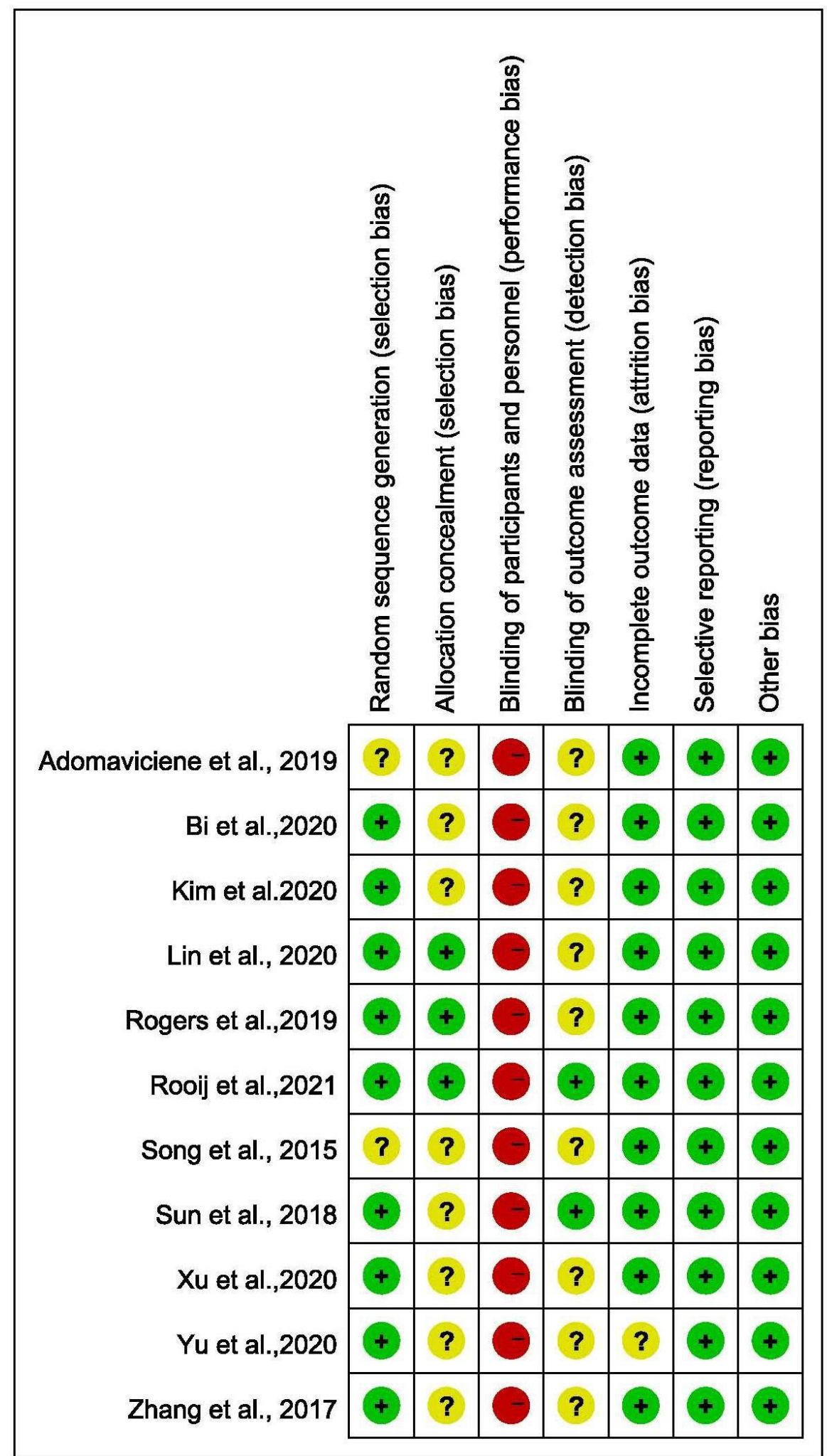

Fig. 2. Summary of risk-of-bias distribution across studies. 


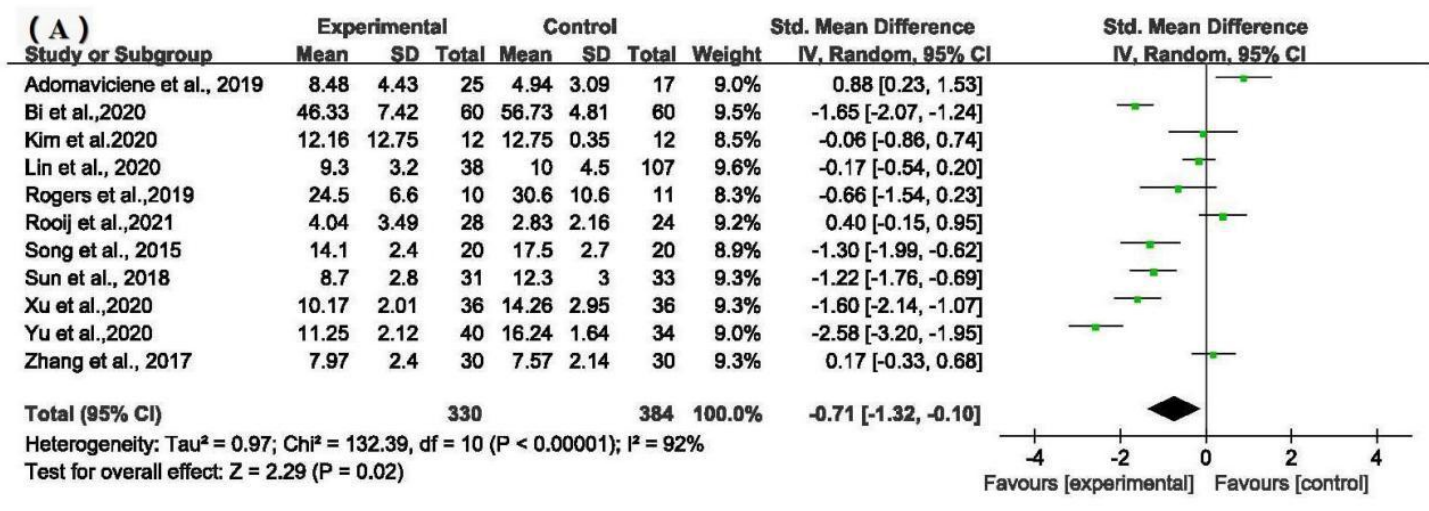

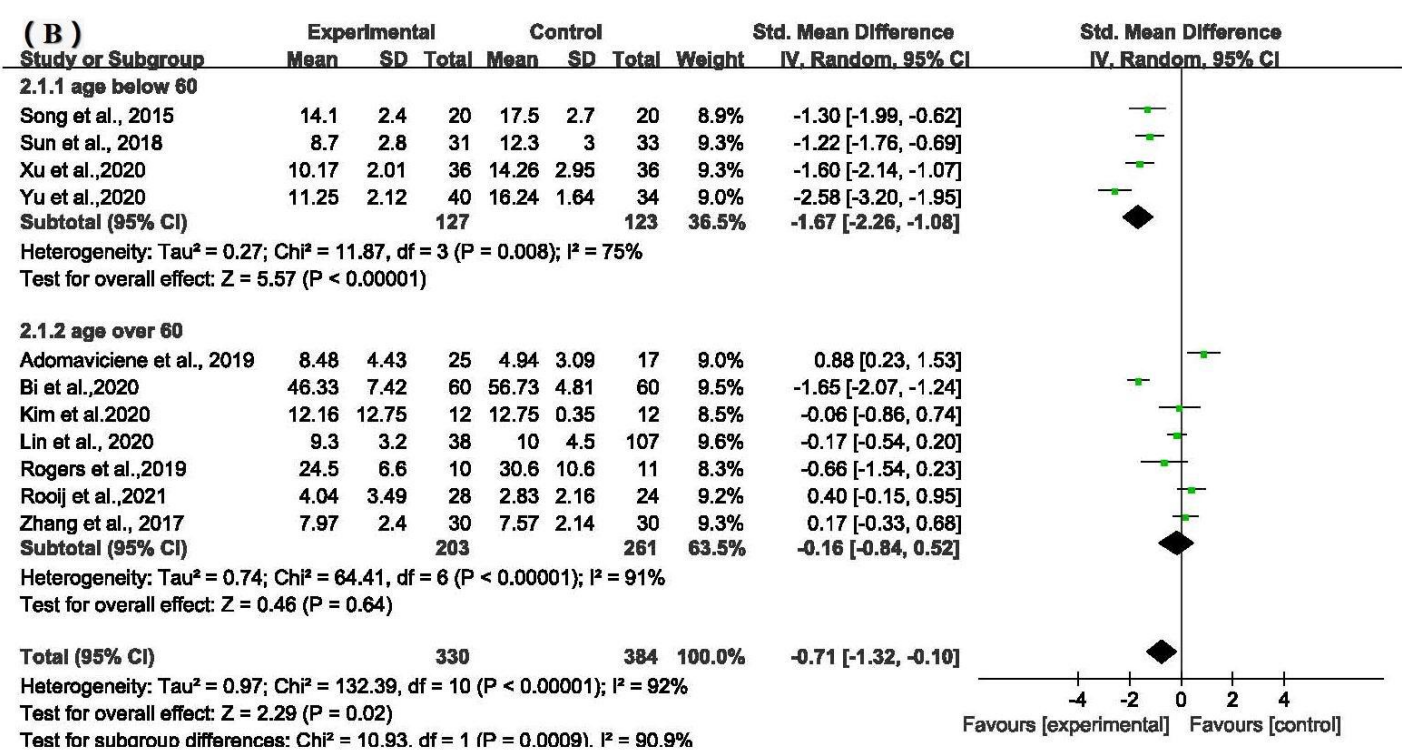

(C) Experimental Control Std. Mean Difference IV. Random, 95\% C Std. Mean Difference Study or Subgroup Mean SD Total Mean $\begin{array}{lrrrrrrr}\text { Bi et al.,2020 } & 46.33 & 7.42 & 60 & 56.73 & 4.81 & 60 & 13.4 \% \\ \text { Song et al., 2015 } & 14.1 & 2.4 & 20 & 17.5 & 2.7 & 20 & 12.2 \% \\ \text { Sun et al., 2018 } & 8.7 & 2.8 & 31 & 12.3 & 3 & 33 & 12.9 \%\end{array}$ $\begin{array}{llrl}\text { Subtotal }(95 \% \mathrm{Cl}) & 111 & 113 & 38.5 \%\end{array}$ Heterogeneity: $\mathrm{Tau}^{2}=0.00 ; \mathrm{Chi}^{2}=1.76, \mathrm{df}=2(\mathrm{P}=0.41) ; \mathrm{l}^{2}=0 \%$ Test for overall effect: $Z=9.62(P<0.00001)$

2.2.2 duration of the Intervention below 8 weeks

$\begin{array}{lrrrrrrr}\text { Kim et al.2020 } & 12.16 & 12.75 & 12 & 12.75 & 0.35 & 12 & 11.6 \% \\ \text { Rogers et al.,2019 } & 24.5 & 6.6 & 10 & 30.6 & 10.6 & 11 & 11.1 \% \\ \text { Rooij et al.,2021 } & 4.04 & 3.49 & 28 & 2.83 & 2.16 & 24 & 12.8 \% \\ \text { Xu et al.,2020 } & 10.17 & 2.01 & 36 & 14.26 & 2.95 & 36 & 12.9 \% \\ \text { Zhang et al., 2017 } & 7.97 & 2.4 & 30 & 7.57 & 2.14 & 30 & 13.0 \% \\ \text { Subtotal (95\% Cl) } & & & 116 & & & 113 & 61.5 \%\end{array}$

Heterogeneity: $\mathrm{Tau}^{2}=0.73 ; \mathrm{Chi}^{2}=33.31, \mathrm{df}=4(\mathrm{P}<0.00001) ;\left.\right|^{2}=88 \%$ Test for overall effect: $Z=0.84(P=0.40)$

Total $(95 \% \mathrm{Cl})$ 227

$-1.65[-2.07,-1.24]$

$-1.30[-1.99,-0.62]$

$-1.22[-1.76,-0.69]$

$-1.46[-1.75,-1.16]$

IV. Random, $95 \% \mathrm{Cl}$

Heterogeneity: $\mathrm{Tau}^{2}=0.71 ; \mathrm{Chi}^{2}=64.86, \mathrm{df}=7(\mathrm{P}<0.00001) ; \mathrm{I}^{2}=89 \%$

Test for overall effect: $Z=2.36(P=0.02)$

Test for subaroun differences: $\mathrm{Ch}^{2}=6.41 . \mathrm{df}=1(\mathrm{P}=0.01) . \mathrm{I}^{2}=84.4 \%$

$-0.06[-0.86,0.74]$

$-0.66[-1.54,0.23]$

$0.40[-0.15,0.95]$

$-1.60[-2.14,-1.07]$

$0.17[-0.33,0.68]$
$-0.35[-1.15,0.46]$

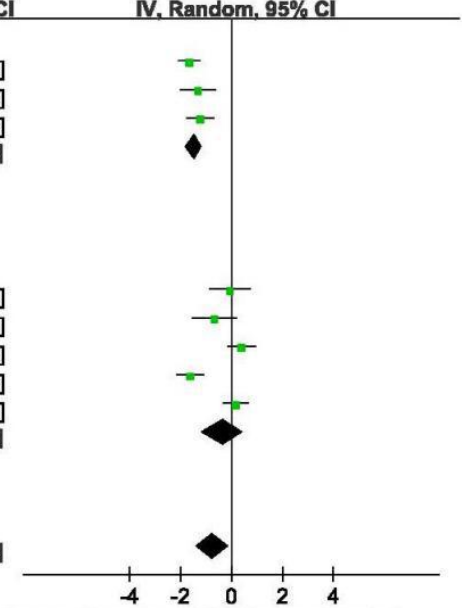

Favours [experimental] Favours [control] 


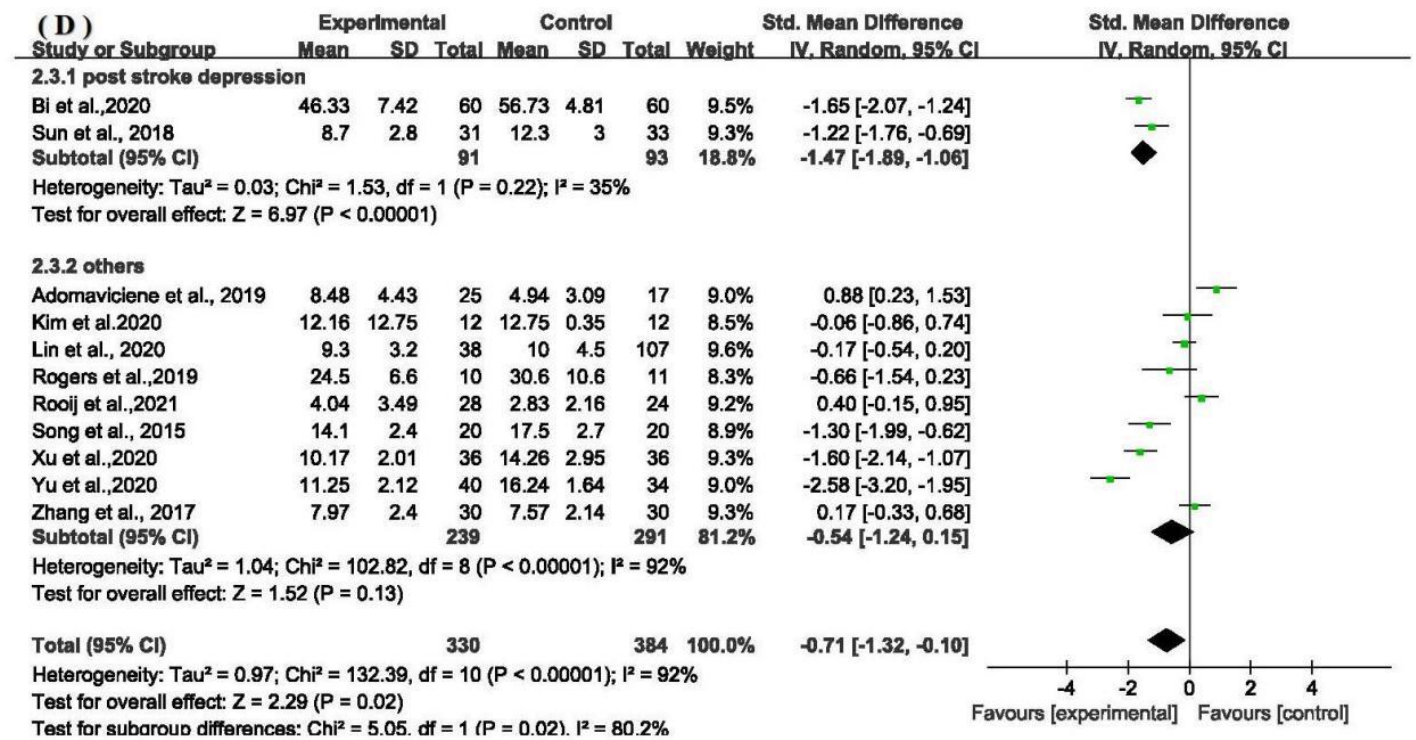

Fig.3. (A) Forest plot of the effect of VR on depression. (B) Forest plot of the effect of VR subjects' age on depression. (C) Forest plot of the effect of VR intervention duration on depression. (D) Forest plot of the effect of VR subjects' types on depression.

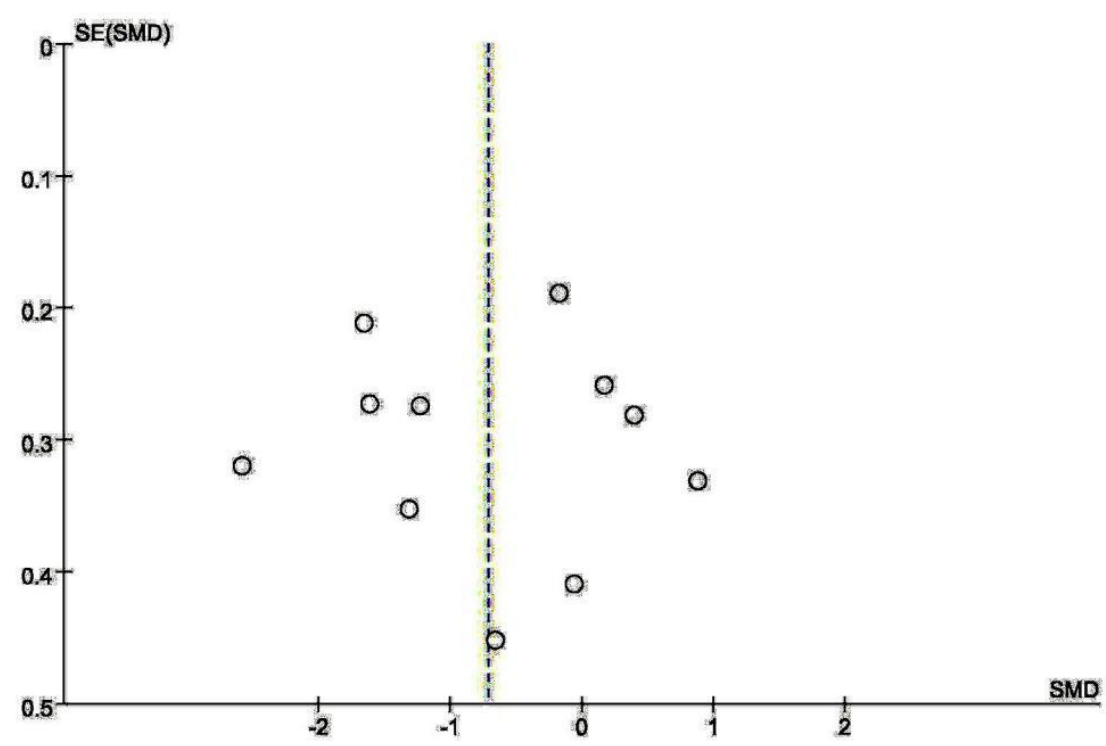

Fig. 4. Funnel plot of the effect of VR on depression.

Four of the subjects are under the age of 60 and seven of the subjects are over 60 years. As shown in Fig.3(B), the results revealed that depression scores are significantly reduced in participants' ages under 60 years than controls (pooled effect size $=-1.67,95 \%$ CI: $-2.26,-1.08)$. Significant heterogeneity was observed among the studies $\left(I^{2}=75 \%, p<0.00001\right)$. Depression scores was not significantly decreased in 
participants' ages over 60 years (pooled effect size $=-0.16,95 \% \mathrm{CI}:-0.84,0.52$ ). Significant heterogeneity was observed among the studies $\left(I^{2}=91 \%, p<0.00001\right)$.

For the duration of the intervention, three RCTs lasted longer than eight weeks, five RCTs were 1ess than eight weeks, while the remaining three RCTs didn't report duration of the intervention. As shown in Fig.3(C), the results of this meta-analysis revealed that intervention longer than eight weeks of RCTs were statistically significantly reduced than controls (pooled effect size $=-1.46,95 \%$ CI: $-1.75,-1.16$,). Significant heterogeneity was observed among the studies $\left(I^{2}=0 \%, p<0.0001\right)$. However, intervention less than eight weeks of RCTs were not significantly decreased (pooled effect size $=-0.35,95 \%$ CI: $-1.15,0.46$ ). Significant heterogeneity was observed among the studies $\left(I^{2}=88 \%, p<0.00001\right)$.

For different types of participants, two RCTs included people with post stroke depression, while the remaining nine RCTs included people with different types of strokes. As shown in Fig.3(D), The results revealed that depression scores are significantly reduced in participants with post stroke depression than controls (pooled effect size $=-1.47,95 \%$ CI: $-1.89,-1.06)$. Significant heterogeneity was not observed among the studies $\left(I^{2}=35 \%, p<0.00001\right)$. Depression scores was not significantly decreased in participants with different types of strokes (pooled effect size $=-0.54$, 95\% CI: $-1.24,0.15)$. Significant heterogeneity was observed among the studies $\left(I^{2}=\right.$ $92 \%, p<0.00001)$.

\section{Discussion}

Our meta-analysis systematically reviews currently available articles and included 11 studies with 752 patients to evaluate the effect of VR-based physical and psychological exercise on depression. The research results show the VR-based physical and psychological exercise is more effective at decreasing depression scores than control group in depression.

A subgroup analysis of patients with different types of strokes shows that only patients with post stroke depression apparently benefited from VR treatment for depression. The subgroup analysis of age shows that for subjects aged under 60, VR 
can effectively reduce depression scores compared with control group, and that, for people aged over 60, no difference is observed. For some older people, contacting VR technology has a challenging due to the visual and auditory changes ${ }^{[38]}$. This may be because older people have a difficulty to adapt the new treatment regimen. The subgroup analysis of intervention duration revealed that intervention longer than eight weeks of RCTs were statistically significantly reduced than control group, and intervention less than eight weeks of RCTs not significantly decreased. The research results of Hsin-Yen et al. revealed that the total intervention duration had a significant effect on the outcome of depression.

VR as a therapeutic tool is rapidly popularized and widespread used due to its novel training methods and ability to provide personalized rehabilitation training ${ }^{[27]}$. At present, various professional technology platforms and treatment schemes based on VR are also under active development and research ${ }^{[29]}$. The research results in recent decades showed that VR technology can be used to treat phobias, stress and pain. But few has tried to develop VR anti-depressant interventions. Compared with traditional rehabilitation training, the VR technology can precisely provide more individualized rehabilitation training programs according to the disease characteristics of different patients and can upload the training data on the internet in real-time. Through the data synchronization between different devices to improve the rehabilitation effect, the VR can also promote interaction between patients and the health system ${ }^{[6]}$.

Currently, no research results show which form of VR technical training or which treatment intensity has the best effect, and there is also a lack of guidelines on the VR development process. In future studies, the same interventions for patients having the same disease can be developed to eliminate high heterogeneity ${ }^{[29]}$. Few articles have evaluated or described feelings of immersion during treatment. The feelings of immersion should be used as an indicator for observation in future research, and the system needs to be to support improved outcomes to clarify how immersive and sophisticated. Recently, commercialized VR has developed rapidly, so, 
it is important to consider the cost, feasibility and accessibility of VR equipment ${ }^{[39]}$. Few articles report the cost of VR rehabilitation training and the economic benefits of this type's training have not been compared with the control group. In future studies, the cost of different type rehabilitation training should be used as an indicator for observation $^{[29]}$. VR may also be used to alleviate depression symptoms and prevent depression in healthy people with some clinically related depression symptoms or sub-domain depression in the future. Based on evidence-based treatment techniques, consumer-targeted VR interventions have great potential to have an impact on the public's psychological health.

There were some limitations in this study that should be noted. Although a detailed literature search had been done, it must be admitted that there is still the possibility of study omission, such as gray literature. In addition, it is also different in the VR intervention forms, training time and dosage, training intensity and outcome evaluation indexes adopted in the included studies. In addition, it is not quite the same that VR technology equipment used and the conventional physical rehabilitation mode implemented by the control group in each study.

Above different may be the reason for high heterogeneity of results. Compared with VR interventions for phobias, pain and stress, the field of anti-depressive VR applications is in its early stages, which constitutes an important limitation to the current state of research. Due to the particularity of VR technology interventions, the blind method is difficult to patients in the experimental group, which may lead to the deviation of subjective data reported by patients in the result evaluation.

\section{Conclusions and implications}

The current meta-analysis indicated the virtual reality-based physical and psychological exercise has a significant effect on depression in stroke patients compared to controls. The study showed an outstanding reduction in depression for aged under 60 participants and intervention longer than eight weeks. This rehabilitation technology, suitable for promotion in family and community, has advantages of saving manpower and low technical requirements. However, this study 
also has some limitations and deficiencies. There were only 11 studies in this paper. So, further confirmation in large clinical trials is needed. At the same time, clinical studies of different ages and different intervention time also need further in-depth study.

Funding

The 11th China Postdoctoral Science Fund special funding [2018T110235]; The National key R\&D plan subtask [2018FYC1706603-05].

Declaration of Competing Interest

No conflict of interest exits in the submission of this manuscript. All the analyses were based on previously published studies. All authors were approved the manuscript for publication. I would like to declare on behalf of my co-authors that the work described was original research that has not been published previously, and not under consideration for publication elsewhere, in whole or in part. All the authors listed have approved the manuscript that is enclosed.

Acknowledgments

The authors thank the researchers who conducted the studies and the experts for their valuable opinions.

Supplementary Appendix 1 and 2

Supplementary material related to this article can be found in the online version. Reference

[1]Szczepanska-Gieracha, J., Cieślik, B., Rutkowski, S., Kiper, P., Turolla, A., 2020. What can virtual reality offer to stroke patients? A narrative review of the literature. NeuroRehabilitation. (47), 109-120.

[2]Rooij, I. J. M. D., Port, I. G. L. V., Visser-Meily, J. M. A., Meijer, J. W. G., 2019. Virtual reality gait training versus non-virtual reality gait training for improving participation in subacute stroke survivors: study protocol of the ViRTAS randomized controlled trial. Trials. 20(1), 89. 
[3]Ezema, C. I., Akusoba, P. C., Nweke, M. C., Uchewoke, C. U., Agono, J., Usoro, G., 2019. Influence of Post-Stroke Depression on Functional Independence in Activities of Daily Living. Ethiop J Health Sci. 29(1), 841-846.

[4]Ghaffari, A., Akbarfahimi, M., Rostami, H. R., 2020. Discriminative factors for post-stroke depression. Asian J Psychiatr. (48), 101863.

[5]Lin, R.C., Chiang, S. L., Heitkemper, M. M., Weng, S. M., Lin, C. F., Yang, F. C., Lin, C. H., 2020. Effectiveness of Early Rehabilitation Combined With Virtual Reality Training on Muscle Strength, Mood State, and Functional Status in Patients With Acute Stroke: A Randomized Controlled Trial. Worldviews Evid Based Nurs. 17(2), 158-167.

[6]Schöttke, H., Giabbiconi, C. M., 2015. Post-stroke depression and post-stroke anxiety: prevalence and predictors. International psychogeriatrics. 27,1805-1812.

[7]Kim, J. L., Cho, J., Park, S., Park, E. C., 2015. Depression symptom and professional mental health service use. BMC psychiatry, 15 (2015) 261.

[8]Ma, C., Pavlova, M., Liu, Y., Liu, Y., Huangfu, C., Wu, S., Gao, X., 2017. Probable REM sleep behavior disorder and risk of stroke: A prospective study. Neurology. 88(19), 1849-1855.

[9]Robinson, R. G., Jorge, R. E., 2016. Post-Stroke Depression: A Review. Am J Psychiatry. 173(3), 221-231.

[10]Medeiros, G. C., Roy, D., Kontos, N., Beach, S. R., 2020. Post-stroke depression: A 2020 updated review. Gen Hosp Psychiatry., 66, 70-80.

[11]Jyotirekha Das, Rajanikant G K. Post stroke depression: The sequelae of cerebral stroke. Neurosci Biobehav Rev., 90 (2018) 104-114.

[12]Hongting, B., Pingan, Q., Xinke, L., 2020. Effect of virtual reality psychological rehabilitation on recovery of daily living ability in patients with post-stroke depression. Mod Pract Med. 32, 1419-1420.

[13]Carvalho, A. F., Sharma, M. S., Brunoni, A. R., Vieta, E., Fava, G. A., 2016. The Safety, Tolerability and Risks Associated with the Use of Newer Generation Antidepressant Drugs: A Critical Review of the Literature. Psychother Psychosom. 
85(5), 270-288.

[14]Fodor, L. A., Coteț, C. D., Cuijpers, P., Szamoskozi, S., David, D., Cristea, I. A., 2018. The effectiveness of virtual reality based interventions for symptoms of anxiety and depression: A meta-analysis. Sci Rep. 8(1), 10323.

[15]Tan, H. L. E., Chng, C. M. L., Lau, Y., Klainin-Yobas, P., 2021. Investigating the effects of a virtual reality-based stress management programme on inpatients with mental disorders: A pilot randomised controlled trial. Int J Psychol. 56(3) () 444-453. [16]Sohn, B. K., Hwang, J. Y., Park, S. M., Choi, J. S., Lee, J. Y., Lee, J. Y., Jung, H. Y., 2016. Developing a Virtual Reality-Based Vocational Rehabilitation Training Program for Patients with Schizophrenia. Cyberpsychol Behav Soc Netw. 19(11), 686-69.

[17]Botella, C., Fernández-Álvarez, J., Guillén, V., García-Palacios, A., Baños, R., 2017. Verónica Guillén, et al. Recent Progress in Virtual Reality Exposure Therapy for Phobias: A Systematic Review. Curr Psychiatry Rep. 19(7), 42.

[18]V Mitrousia, O Giotakos. Virtual reality therapy in anxiety disorders. 2016. Psychiatriki. 27(4), 276-286.

[19]Otte, C., 2011. Cognitive behavioral therapy in anxiety disorders: current state of the evidence. Dialogues Clin Neurosci., 13(4) (2011) 413-421.

[20]Norton, P. J., Price, E. C., 2007. A meta-analytic review of adult cognitivebehavioral treatment outcome across the anxiety disorders. J Nerv Ment Dis., 195(6), $521-531$.

[21]Monteiro-Junior, R. S., Figueiredo, L. F. D. S., Maciel-Pinheiro, P. D. T., Abud, E. L. R., Engedal, K., Barca, M. L., Nascimento, O. J. M., Laks, J., Deslandes, A. C., 2017. Virtual Reality-Based Physical Exercise With Exergames (PhysEx) Improves Mental and Physical Health of Institutionalized Older Adults. J Am Med Dir Assoc. 18(5), 454.e1-454.e9.

[22] Sun Yan, Li Liang, Zeng Ming, Tao Linhua, Fu Jianming, Bu Yifeng, Gu Xudong, Yao Yunhai. 2018. Effect of virtual reality training combined with psychological intervention on post-stroke depression. Chin J Rehabil Med. 33(6), 
727-729.

[23]Rogers, J. M., Duckworth, J., Middleton, S., Steenbergen, B., Wilson, P. H., 2019. Elements virtual rehabilitation improves motor, cognitive, and functional outcomes in adult stroke: evidence from a randomized controlled pilot study. J Neuroeng Rehabil. 16(1), 56 .

[24]Bevilacqua, R., Maranesi E., Riccardi, G. R., Donna, V. D., Pelliccioni, P., Luzi, R., Lattanzio, F., Pelliccioni, G., 2019. Non-Immersive Virtual Reality for Rehabilitation of the Older People: A Systematic Review into Efficacy and Effectiveness.

J Clin Med. 8(11), 1882.

[25]Lei, C., Sunzi, K., Dai, F., Liu, X., Wang, Y., Zhang, B., He, L., Ju, M., 2019. Effects of virtual reality rehabilitation training on gait and balance in patients with Parkinson's disease: A systematic review. PloS one. 14(11), e0224819.

[26]Laver, K. E., Lange, B., George, S., Deutsch, J. E., Saposnik, G., Crotty, M., 2017. Virtual reality for stroke rehabilitation. Cochrane Database Syst Rev. 11(11), CD008349.

[27]Torrisi, M., Maresca G., Cola, M. C. D., Cannavò, A., Sciarrone, F., Silvestri, G., Bramanti, A., Luca, R. D., Calabrò, R. S., 2019. Using telerehabilitation to improve cognitive function in post-stroke survivors: is this the time for the continuity of care? Int J Rehabil Res. 42(4), 344-351.

[28]Li, J., Theng, Y. L., Foo, S., 2014. Game-based digital interventions for depression therapy: a systematic review and meta-analysis. Cyberpsychol Behav Soc Netw. 17(8), 519-527.

[29]Fodor, L. A., CoteT, C. D., Cuijpers, P., Szamoskozi, S., David, D., Cristea, I. A., 2018. The effectiveness of virtual reality based interventions for symptoms of anxiety and depression: A meta-analysis. Sci Rep. 8(1), 10323.

[30]Yen, H. Y., Chiu, H. L., 2021. Virtual Reality Exergames for Improving Older Adults' Cognition and Depression: A Systematic Review and Meta-Analysis of Randomized Control Trials. J Am Med Dir Assoc. 22(5), 995-1002.

[31]Moher D., Liberati A., Tetzlaff J., Altman D. G., Group P., 2009. Preferred 
reporting items for systematic reviews and meta-analyses: the PRISMA statement. J Clin Epidemiol. 62(10), 1006-1012.

[32]Higgins, J. P. T., Thompson, S. G., Deeks, J. J., Altman, D. G., 2003. Measuring inconsistency in meta-analyses. BMJ. 327(7414), 557-560.

[33]Kim, J. W., Kim, J. H., Lee, B. H., 2020. Effects of virtual reality-based core stabilization exercise on upper extremity function, postural control, and depression in persons with stroke. Phys Ther Rehabil Sci. 9, 131-139.

[34]De Rooij IJM, Van de Port IGL, Punt M, Abbink-van Moorsel PJM, Kortsmit M, van Eijk RPA, Visser-Meily JMA, Meijer JG., 2021. Effect of Virtual Reality Gait Training on Participation in Survivors of Subacute Stroke: A Randomized Controlled Trial. Phys Ther. 101(5), pzab051.

[35]Xu N. J., He Y. G., 2020. Effects of Virtual reality rehabilitation on balance ability in patients with pusher syndrome after stroke. Henan Med Res. 29(14), 2536-2538.

[36]Yu M. Q., Zhu J. G., Ren H., Wang X. J., Yin H. C., Yan H. Y., Xi H. Y., 2021. Effect of stroke unit combined with task-oriented training on young patients with ischemic stroke. Neural Injury And Functional Reconstruction. 16, 225-227.

[37]Zhang X. X., Zheng Y., Zhan X. L., Ye S. Z., Hu H., 2017. Effect of early virtual reality training on the rehabilitation of stroke patients with hemiplegia. Chin J Mod Nurs. 23, 3704-3708.

[38]Dermody, G., Whitehead, L., Wilson, G., Glass, C., 2020. The Role of Virtual Reality in Improving Health Outcomes for Community-Dwelling Older Adults: Systematic Review. J Med Internet Res. 22, e17331.

[39]Mallari, B., Spaeth, E. K., Goh, H., Boyd, B. S., 2019. Virtual reality as an analgesic for acute and chronic pain in adults: a systematic review and meta-analysis. J Pain Res. 12, 2053-2085. 


\section{Supplementary Files}

This is a list of supplementary files associated with this preprint. Click to download.

- SupplementaryAppendix.pdf 